\title{
Notas à contribuição da geomorfologia para a compreensão das transformações bruscas na paisagem da Região Serrana (RJ)
}

\section{Professor Marcelo Motta}

A presente exposição busca trazer para o debate a contribuição da geomorfologia no entendimento de transformações bruscas da paisagem. Ao mesmo tempo, destaca-se a interface entre a ciência geomorfológica e o planejamento, sobretudo urbano, na medida em que a perspectiva é a de explicitar distintos processos que se sobrepõem no momento das referidas transformações, cujas implicações são danos muitas vezes irreparáveis sobre o ambiente natural, incluídos igualmente aqueles que repercutem sobre a vida humana.

A área em estudo corresponde à Região Serrana, localizada no Estado do Rio de Janeiro, marcadas pela recorrência de movimentos de massa, portanto reconhecidamente, a vulnerabilidade ambiental é assim destacada. Desse modo, pressupõe-se a intervenção da geomorfologia como importante instrumento de planejamento, com o intuito de corrigir a degradação já em curso, bem como a prevenção de desastres futuros.

Figura 1 - Localização das Principais áreas atingidas 


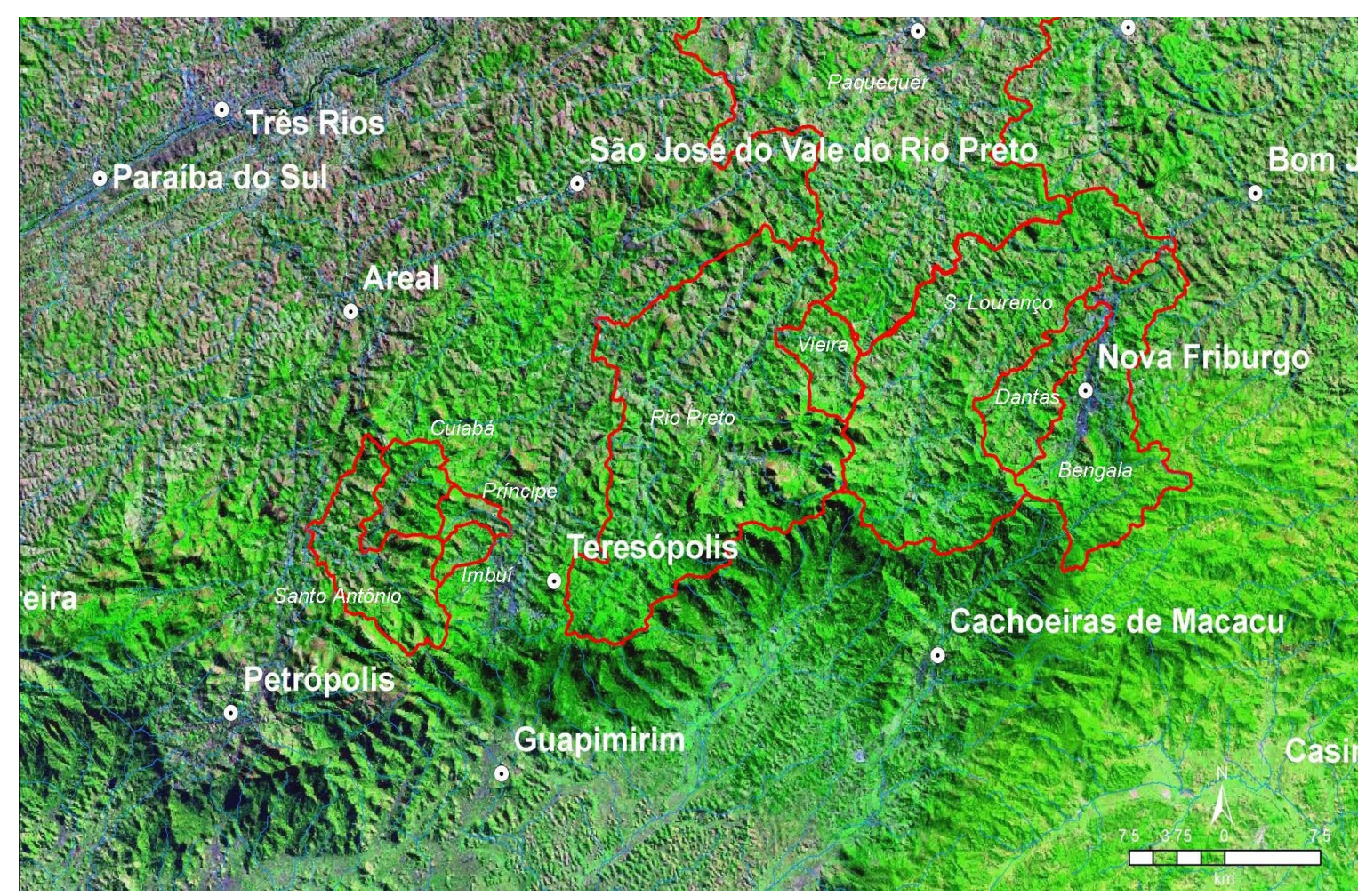

Fonte: Organizado pelo autor (2011)

A situação da Região Serrana (do Estado do Rio de Janeiro) é muito particular, caracterizada pela presença de uma diversidade de encostas, com presença de fundos de vales côncavos e convexos. As imagens a seguir, nos ajudarão na explicitação das situações de vulnerabilidade da referida região, enfatizando-se as complexas interações de fenômenos naturais, acrescidos das ações humanas, reveladas pelo processo de povoamento da referida região na perspectiva do uso do solo.

Foto 1 - Caracteres naturais mais marcantes da Região Serrana: presença de encostas com vales côncavos e convexos 


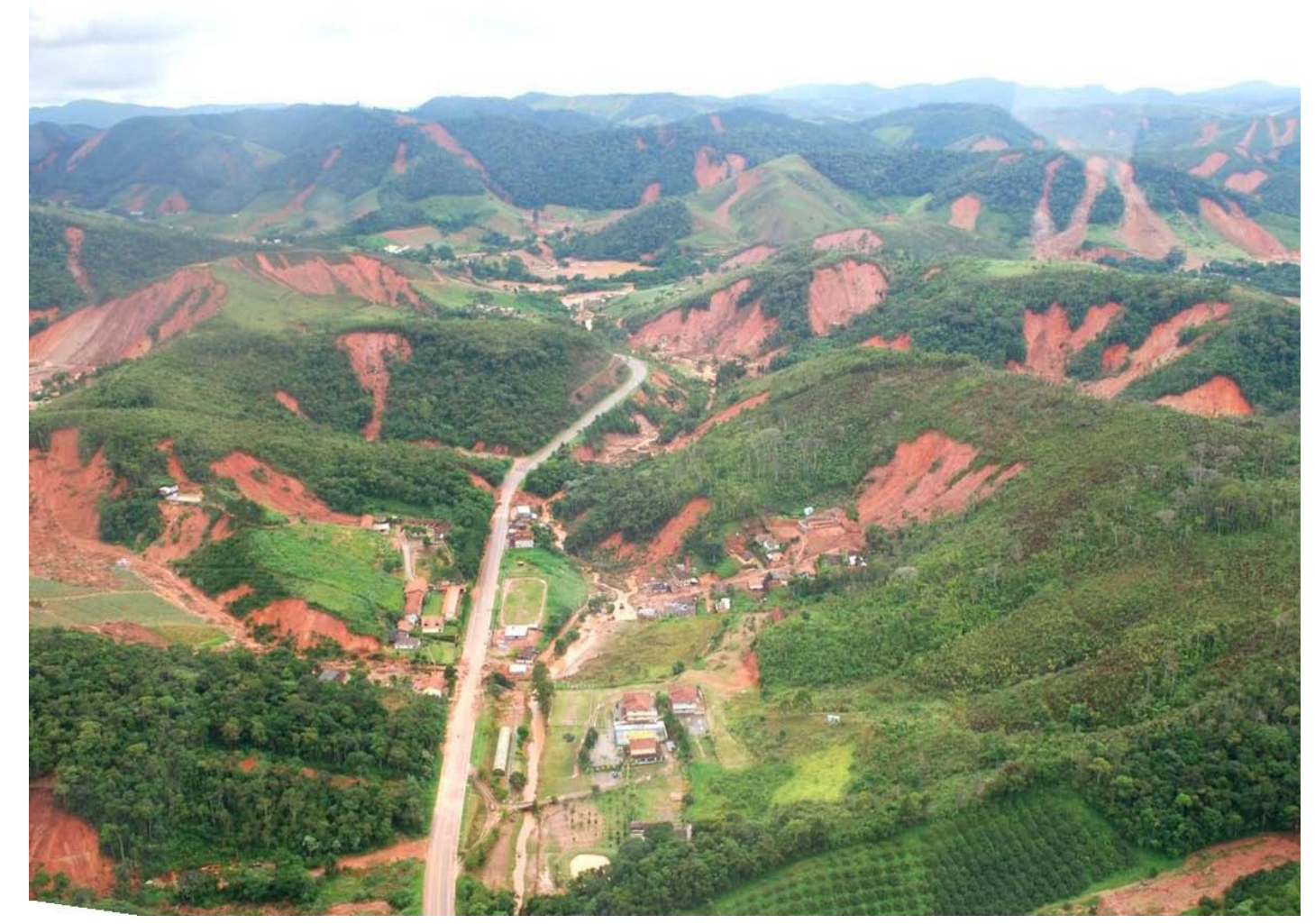

Fonte: Foto tomada pelo o autor, após o evento (2011)

Estudar as complexas interações da paisagem permite vislumbrar a vulnerabilidade ambiental. Utilizando-se de fotografias áreas, dados meteorológicos, notações sobre a disposição do relevo, estudos sobre a litologia, observação sobre a declividade, análise das características do solo, estudos de dados relacionados ao comportamento hidrológico, levantamento das características fitogeográficas, uma vez em interação revelam a dinâmica das transformações da paisagem. Superam-se, desta maneira, meras descrições e especulações ao mesmo tempo em que fica assegurada a prevenção de desastres. Acreditamos que ao contemplar essa complexa interação, observa-se o importante papel da geomorfologia, pois não se pressupõe uma paisagem estática, ao contrário, a superfície terrestre está sempre em constante transformação.

Um dado importante, contudo, está relacionado ao tempo. Transformações podem ser lentas do ponto de vista da escala da história humana, mas é necessário considerar que uma série de fatores pode concorrer para determina situação, estando relacionada à escala do tempo geológico, pois a litologia, a disposição do relevo, a configuração da paisagem supõe uma evolução que remete à história geológica da Terra. Entretanto, mudanças bruscas são observadas e em geral, são tratadas como 
catastróficas, dado o caráter trágico que nelas resulta, exemplificado pelo caso de Nova Friburgo.

Consideremos a foto abaixo, que nos mostra deslizamentos ocorridos na Região Serrana. Corresponde a uma área onde se localiza o teleférico, importante ponto turístico da cidade de Nova Friburgo, junto está o hotel que leva o seu nome. Na parte baixa está situada a conhecida Praça do Suspiro, seguida pela Rua Spinelli, já na parte central de Friburgo ${ }^{1}$.

Foto 2 - Aspectos da Praça do Suspiro, após o evento de 2011

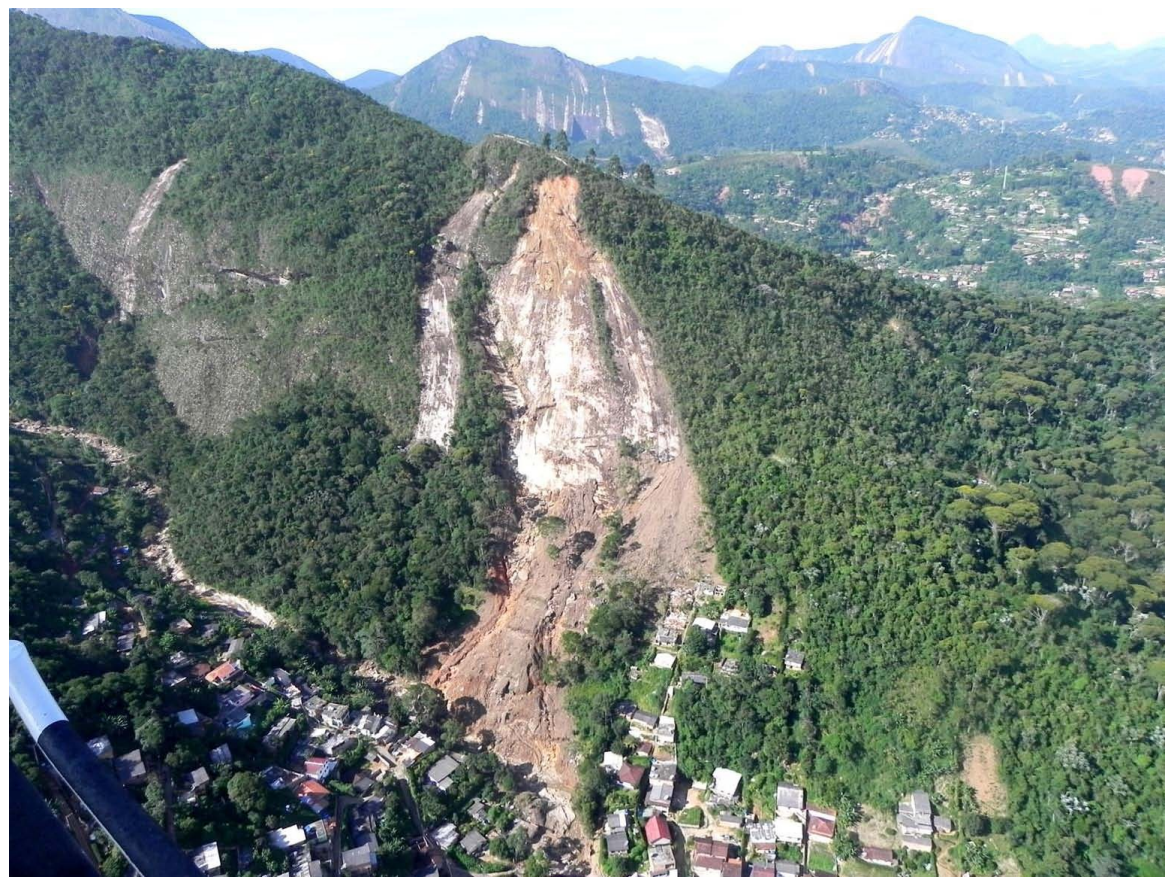

Fonte: Foto tomada pelo autor (2011)

Nesse sentido, ressaltamos a interação humana com a paisagem natural, destacando, na área em estudo, a ocupação das encostas de Friburgo, onde notamos que a ocupação do solo ocorre mesmo em áreas reflorestadas.

É perceptível a quantidade de cortes e intervenções feitas nessas encostas; o planejamento urbano se é que existe (ou a falta dele), a ausência de políticas habitacionais estão, sobremaneira, na base da explicação desses desastres.

\footnotetext{
${ }^{1}$ Nessa localidade houve o falecimento dos três bombeiros que estavam realizando resgates dos moradores desse prédio; uma parte do prédio foi abaixo e esse evento aconteceu na madrugada do dia 12 de janeiro 2011. A maioria da população estava dormindo e foi surpreendida.
} 
A geomorfologia, analisando a disposição dos materiais presentes, o gradiente do relevo, a profundidade e a morfo-estrutura, apresenta instrumentos que podem auxiliar na mitigação desses desastres, conforme apontamos acima.

$\mathrm{Na}$ foto a seguir são notados cortes, fissuras e estradas na mesma encosta. Observa-se ainda a presença de paredões rochosos íngremes. As habitações foram construídas em campos de blocos; a população residente nessa localidade construiu suas casas e, um caso muito particular nos intrigou, quando observamos que, no momento do desastre foi despejado um matacão dentro de uma das casas.

\section{Foto 3 - Ocupação de encostas íngremes por residências}

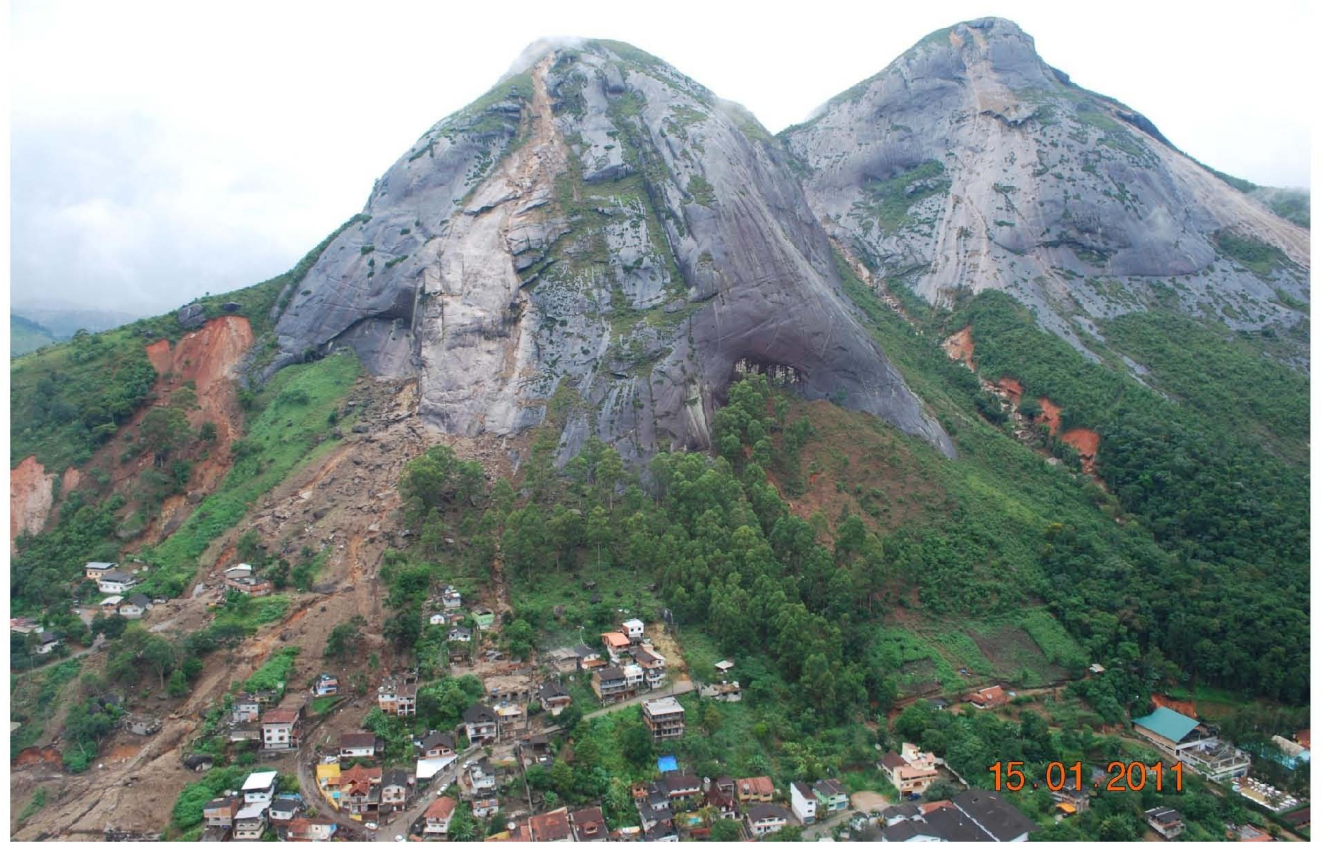

Fonte: Foto tomada pelo autor (2011)

Detenhamo-nos nas morfologias, nas geometrias das encostas e qual a funcionalidade que cada uma destas promove para o deslizamento em ambientes florestados. Há evidências, repetidamente anunciadas, que as áreas mais íngremes são sujeitas potencialmente a deslizamentos, portanto, necessário se faz reconhecer os fatores limitantes a sua ocupação e ao mesmo tempo a necessária mobilização em favor de sua preservação. 
Cabe, então, desmistificar essa ideia geral de que a floresta "não desliza", pois é o contrario: a floresta é um ambiente facilitador de infiltração, mas também atenuador de fluxos de energia. Existem diversos problemas em ambientes florestados. Não se trata aqui de se estar defendendo o desmatamento, pois temos diversos problemas em ambientes desmatados, diversos processos erosivos.

A ocupação em margens fluviais com a presença de cachoeiras ou de kneck point ${ }^{2}$, se traduzem em ocupações, muitas delas próximas a pontos de estrangulamento da rede de drenagem. Potencializa-se a quantidade de deslizamento, causando efeitos destruidores como o que se processou nesse evento ocorrido em Friburgo. À esquerda, como se nota na foto 4 , observamos uma dessas cachoeiras, um knect point, que lançou um elevado volume de água com uma massa de terra originada na parte superior e os habitantes do condomínio não tiveram escapatória.

Foto 4 - Exemplo de um kneck point e suas conseqüências em função de alterações bruscas na dinâmica natural

${ }^{2}$ Knect Point são estrangulamentos naturais da rede de drenagem, caracterizam-se, em geral, por interrupções no seu curso. Se tomarmos um rio e analisar o perfil longitudinal dele percebe-se aonde tem as quedas, são as famosas cachoeiras. É a outra denominação utilizada para cachoeiras e corredeiras e estão incluídas nesta categoria dos Knect Point. São apertos na Rede de drenagem. No vale estrangula, passa um degrau e abre de novo em outra planície. Se olharmos a paisagem de Nova Friburgo - embora também exista em outros lugares - perceberemos que é plena dessas planícies de estrangulamento, sobretudo em áreas montanhosas, só que as planícies são a preferência das ocupações e são justamente as áreas que inundam. 


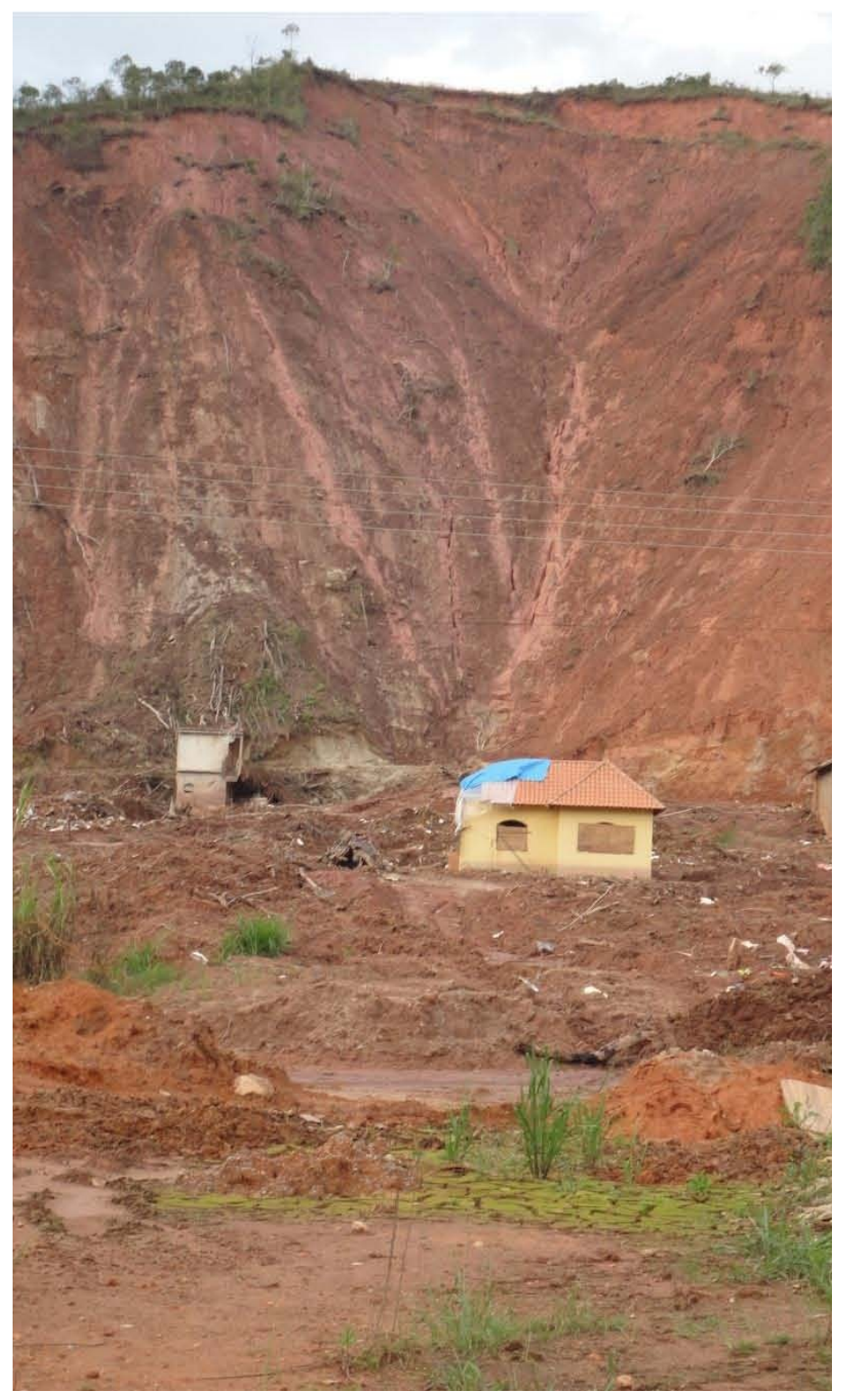

Fonte: Foto do autor (2011)

Nosso procedimento metodológico, então se iniciou com o diagnóstico desse primeiro dia tentando entender o que tinha acontecido. Recorremos, primeiramente, a um contexto geomorfológico da região serrana, onde estabelecemos questionamentos iniciais: o que é essa região serrana? Quais foram às cidades atingidas?

Nas localizações como Petrópolis, Teresópolis e Friburgo, nas partes altas, nas bacias e cabeceiras e no médio curso dessas bacias, onde se localizam São Jose do Vale do Rio Preto, Areal e Bom Jardim, Sumidouro, algumas cidades que estão no médio curso do rio que drenam o reverso da Serra do Mar para o eixo do Rio Paraíba do Sul, verificou-se que a configuração desse relevo tem uma historia geológica e 
geomorfológica que vem desde a colisão continental da África com a América e do continente Gondwano.

Este fenômeno é denominado ciclo brasiliano, definido como um ciclo de colisão continental que metamorfizou todas essas rochas no Estado do Rio de Janeiro formando os gnaisses e os granitos, compondo belíssimas paisagens naturais e belezas geológicas do Rio de Janeiro, marcando certa singularidade no quadro da superfície terrestre, algo comparado ao Grand Canyon, localizado nos Estados Unidos, mas de reconhecida beleza cênica em todo o mundo.

Essas singularidades e suas belezas cênicas são recorrentes na superfície terrestre. No caso brasileiro, notaremos que não há outra pedra da Gávea ou outro Pão de Açúcar ou outro Dois Irmãos. São formações bem peculiares estando intimamente relacionadas até mesmo com a identidade da cidade do Rio de Janeiro, dada a recorrência em que aparecem em seus cartões postais ou mesmo muito presentes em divulgação para turismo.

Após as referidas colisões continentais, ocorreu a abertura do Oceano Atlântico e a quebra dessas rochas todas em alinhamentos serranos como a Serra do Mar, a Serra da Mantiqueira, os Maciços Costeiros e os Grabens. Estes, em particular, são áreas rebaixadas a exemplo do Graben da Guanabara, do Paraíba do Sul e o de Santos, onde se desenvolvem as atividades ligadas às petrolíferas, sendo exemplos mais expressivos os casos de Santos e de Campos.

É importante destacar a formação desse alinhamento, no sentido Leste-Nordeste para as serras e o alinhamento Nordeste para as litologias. Para os tipos de rochas esse alinhamento merece atenção, pois ele foi gerado a partir da colisão da abertura, pois deixaram um plano de fraqueza preferencial para os processos erosivos ocorrerem. Os vales foram, por conseguinte, entalhando simetricamente nessas fraturas. Nessas falhas da abertura do Atlântico se alinharam o relevo e desta forma constituíram-se os principais vales desta região: vale do Piabanha, vale do Rio Preto, do rio Paquequer, do rio Bengala, todos esses rios drenam o reverso da Serra do Mar. Esse trabalho de esculturação destes rios deixou alinhamentos de direção nordeste nestas montanhas e as cidades seguiram esses alinhamentos. Elas foram colonizando esses fundos de vales. $\mathrm{O}$ povoamento e a consequente urbanização, seguiram o alinhamento nordeste. 
Figura 2 - Representação esquemática sobre fotografia área das principais linhas de fraturas, ilustrativas da escultura simétrica e da constituição dos fundos de vale

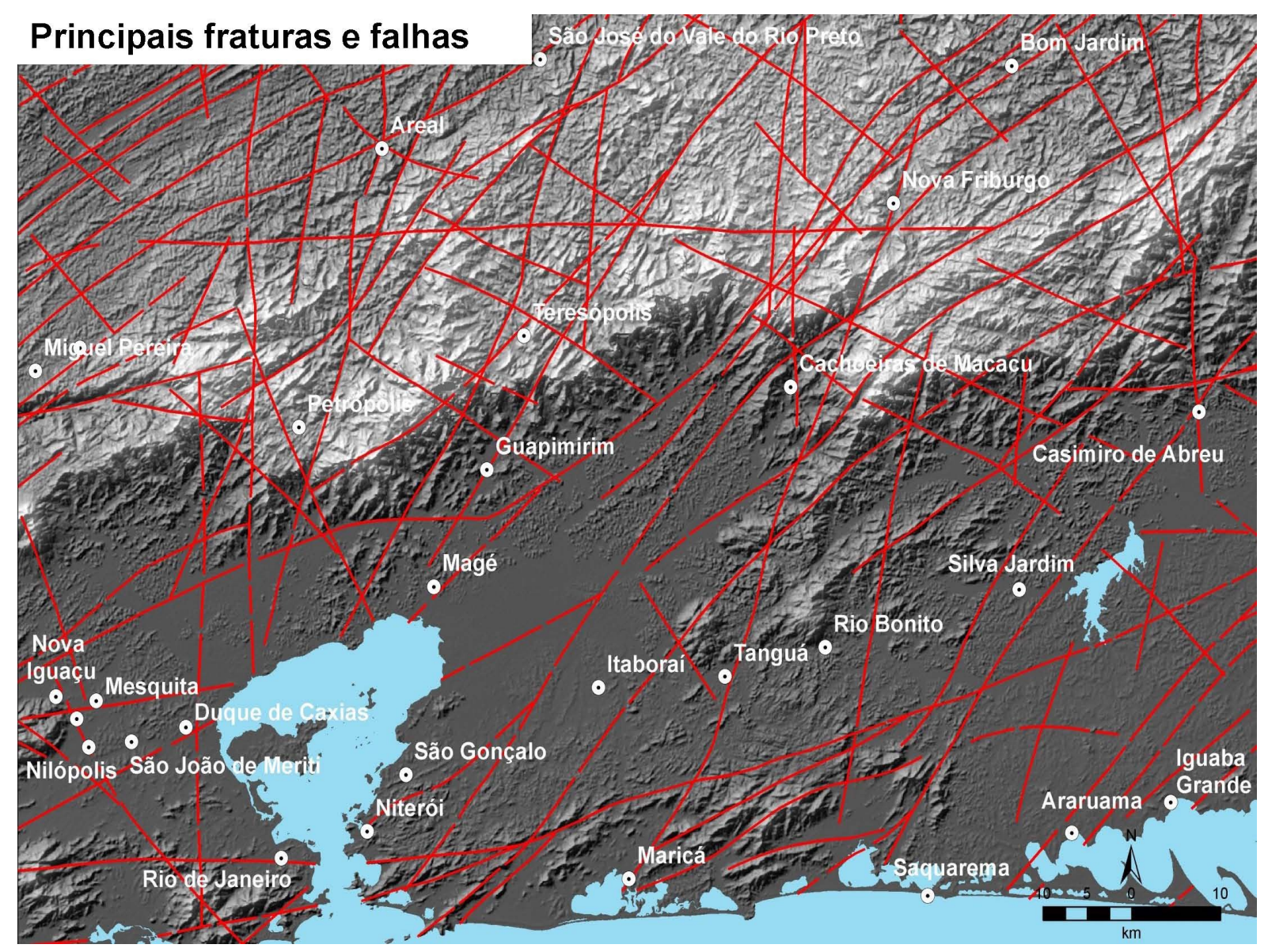

Fonte: Elaborado pelo autor (2012)

Todos os processos de ocupação destes vales são realmente limitados pelas montanhas, as identidades culturais também são dadas pelos vales: os residentes se identificam com os vales: "você mora no Vale boa Esperança", diz um; "eu sou do Vale do São Pedro" dirá outro.

Assim, as identidades territoriais também acabam tendo um vinculo com o relevo, com a sua fisiografia. Nossa análise nos conduziu, a conclusão de que esses alinhamentos no sentido nordeste tiveram uma importante função no evento climático que ocorreu na madrugada do dia 11 para o 12, onde massas de ar polares vinda do Sul se encontram com as massas de ar quente na Região Sudeste formando frentes frias no Rio de Janeiro(um processo natural).

Naquele momento o "clima-tempo" anunciava: está se aproximando uma frente fria e chegou ao Sudoeste, porém, ela está conjugada com um fenômeno vindo de 
Noroeste da massa equatorial amazônica e ainda com um vento originado de oeste, provocado pelo fenômeno do El Nino. Com isso foi drenada uma massa de vapor vinda Amazônia que se condensou pela massa fria vinda do sudoeste. Como resultado houve uma forte descarga de umidade vinda de noroeste que esbarra justamente com o alinhamento nordeste do relevo.

No conjunto, as observações do momento em tela revelaram a configuração de massas de ar e de relevo que definiram alguns exemplos extremos localizados nos principais alinhamentos montanhosos destas três cidades: Petrópolis, Teresópolis e Friburgo. Por acaso, em deslocamentos feitos para Belo Horizonte no dia 18, já se podia perceber estes mecanismos de nuvens que ainda estavam acontecendo e foram tomadas fotografias dessa situação. A foto a seguir, embora esteja muito localizada, é sugestiva da configuração que ora descrevemos.

Foto 6 - Deslocamento das massas de ar com a presença de barreiras orográficas

\section{Entrada das Massas de Ar da ZCAS na região Serrana do Rio de Janeiro}

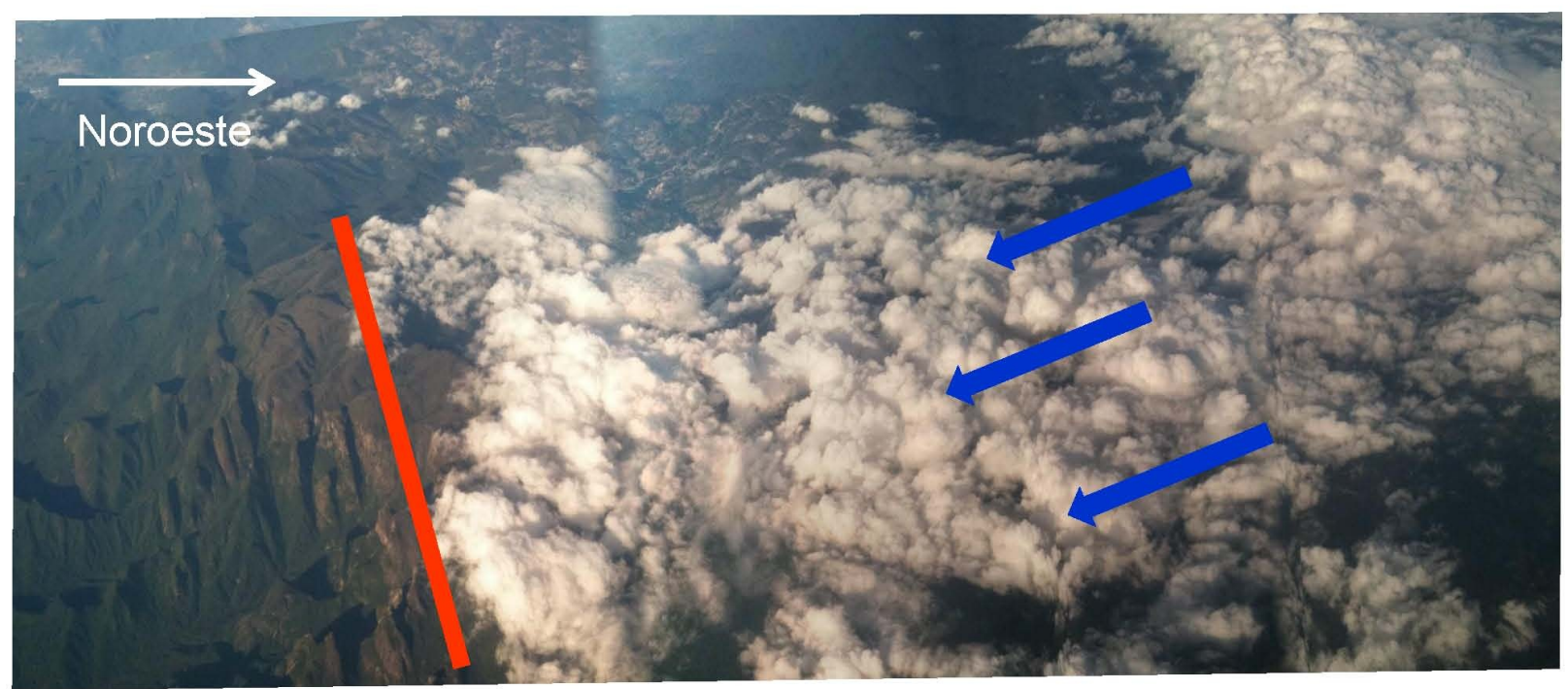

Barreira orográfica formada pela Serra dos Órgãos, que impediu a passagem da chuva do dia 12 para a vertente atlântica da Serra do Mar, concentrando, assim, a precipitação nas cabeceiras dos rios na porção reversa da Serra. Os picos do Açu, Sino, Caledônia, Três Picos, bloquearam o avanço da massa de ar proveniente da Amazônia.

Massas de Ar provenientes da ZCAS

Fonte: Foto do autor (2011) 
Chuvas de noroeste são recorrentes na Região Serrana. Através deste evento (janeiro 2011) houve descarregamento destes índices pluviométricos. Mas, já em novembro ocorreu um pico de chuva que chegou a promover um ensaio de alerta na cidade de Friburgo, e ao chegar janeiro, o evento surpreendeu a população.

Ao se observar a precipitação horária (gráfico 1) percebe-se dois picos nesta precipitação na madrugada: às duas, às três e meia e às quatro da manhã. Justamente, neste horário as pessoais estão completamente despreparadas, não tendo também nenhuma cultura de alerta e de emergência. Partimos, assim, para o mapeamento das bacias de drenagem, mapeamos o rio Bengala, o córrego Dantas que é um córrego importante do rio Bengala, o córrego Vieira, a bacia do rio Paquequer e em Teresópolis na região noroeste da cidade, o rio Príncipe do Induí, onde se localiza a cidade de Posse e Campo Grande que foram cidades muito atingidas.

Gráfico 1 - Demonstração do comportamento pluviométrico em período selecionado.

\section{Pluviosidade $(\mathrm{mm})$ em intervalos de 15 minutos nos dias} 11/01/2011 e 12/01/2011 (Estações INEA-RJ)

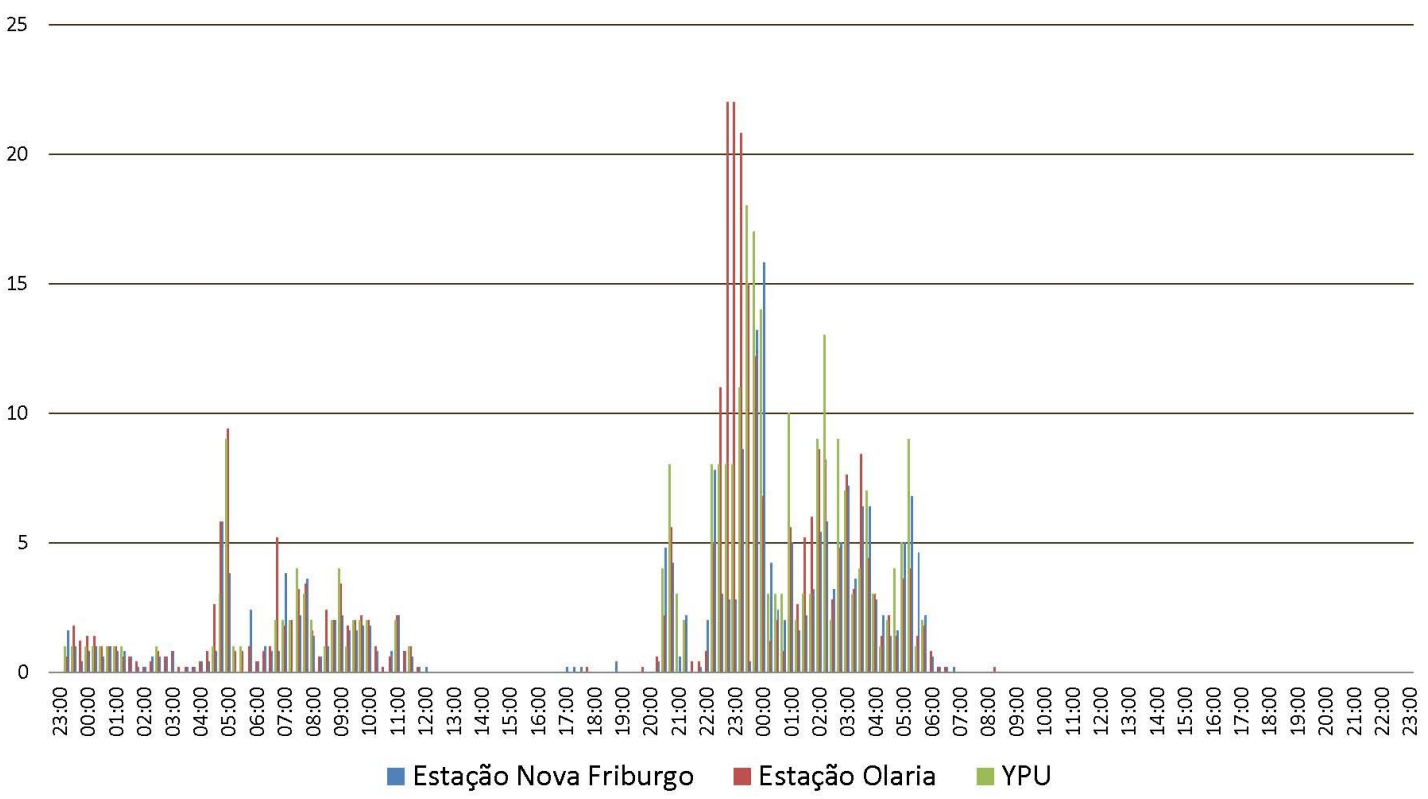

Fonte: Elaborado pelo autor com base na coleta de dados nas estações locais (indicadas no gráfico), 2011

Nesse primeiro momento, o serviço realizado pode ser denominado de identificação de "risco eminente" e então trabalhamos junto com a defesa civil indicando as casas que devem ser evacuadas no momento das chuvas. Esse momento é o mais dramático quando está tudo acontecendo e temos que dar uma resposta rápida. 
Subimos de helicópteros e sobrevoamos a área identificando quais foram os locais atingidos. A seguir elaboramos a imagem abaixo. Esse material é entregue à defesa civil acompanhado de fotos tomadas de helicóptero com a delimitação das casas que tinham que ser evacuadas.

Imagem 1 - Identificação das áreas com cicatrizes e com risco eminente

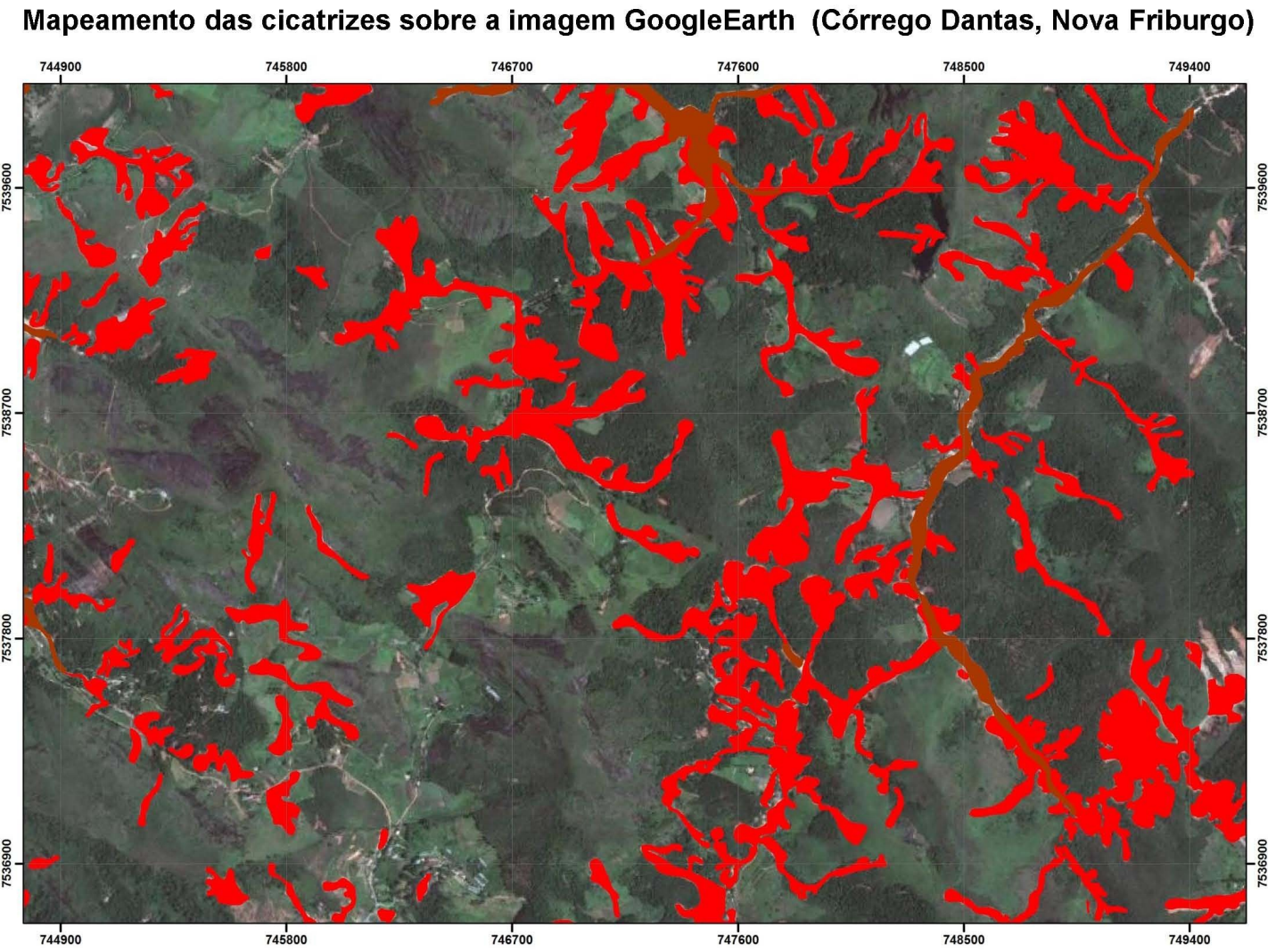

Fonte: Elaborado pelo autor (2011)

É muito comum a população achar que se sua casa não será levada em algum deslizamento e sustentam que sua casa esta firme. Isso, porém, não é verdade: a casa em si pode ate ser bem estruturado, mas o local em que ela foi construída não é estável.

Trabalhadas as imagens destes acontecimentos, verificamos uma seqüência do antes e do depois e com o geoprocessamento, usando modelos digitais, apontamos esses deslizamentos entendendo onde eles estão acontecendo, percebendo as morfologias preferenciais, quais são as geometrias de encostas, onde a população deve ou não deve ocupar. O caso do hospital São Lucas de Nova Friburgo é muito peculiar. Merece um destaque, porque ele está bem no canto de duas corridas paralelas. Um hospital é um equipamento urbano muito importante em um momento deste. E o hospital está 
justamente na rota precipicial de deslizamento daquele paredão rochoso. Um planejamento urbano adequado jamais presumiria a localização de um hospital ali.

Começou-se a gerar os primeiros mapas da catástrofe, e aí então se partiu para as cartas topográficas de 1:50.000 do IBGE georeferenciando todas elas; algumas áreas foram mapeadas à mão. Nós tivemos as primeiras imagens fornecidas em fevereiro pelo Geo Labi e começamos a mapear com mais detalhes, ali o córrego Dantas, a quantidade de cicatrizes é surpreendente: passam de 2500 cicatrizes erosivas (isso na área em que nós mapeamos). Aqui se tem imagens do Google que até hoje estão disponíveis e através dessas imagens conseguimos mapear mais áreas. Notamos o caso da cidade de Conquista que foi muito atingida e ainda o mapa geral, no canto esquerdo está Teresópolis, no lado direito esta Friburgo e a partir disso começamos a estudar a morfologia destas bacias estudando a topografia, a hidrografia e entender como que essas presenças de Knect Point, os já comentados "estrangulamentos". Com isso, se percebeu quais são as principais zonas de fraqueza, onde o deslizamento vai ocorrer e qual tipo de material vai ser removido, o que ele carrega, aonde ele chega e qual é a dimensão que ele vai atingir.

Imagem 2 - Mosaico com identificação de cicatrizes

\section{Cicatrizes sobre o mosaico de imagens GoogleEarth}

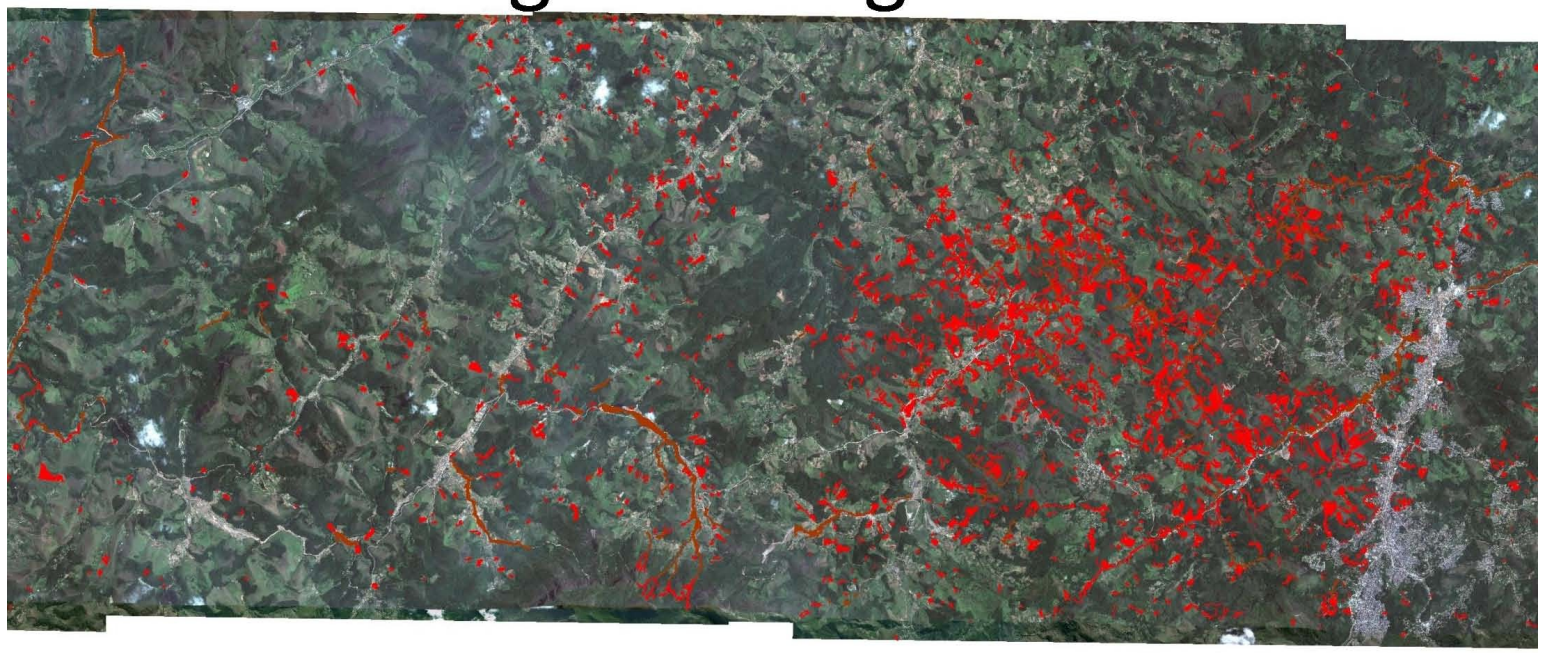

Fonte: organizado pelo autor sobre imagens do GoogleEarth (2011) 
O que é importante perceber nessas historias todas é justamente como ocupar estes espaço, na verdade a dinâmica do relevo, a dinâmica hidrológica, a dinâmica erosiva dessas bacias é muito clara. Os depósitos de bloco são colocados nos seus lugares, as drenagens estão passando, suas planícies de inundação estão delimitadas por depósitos e a população chega e ocupa essas áreas como se isso fosse normal.

A pergunta que cabe é a seguinte: Você lembra a mosca que posou no natal de 2003? Você não lembra a mesma coisa quando o assunto agora é uma montanha que existe a 130 milhões de anos e para ela - eventos naturais, considerando-se a escala do tempo geológico - trata-se de um evento que é corriqueiro; sem querer remeter aos méritos ou não da noção de "natureza animada", vale ressaltar que ela nem se lembra de humanos, seres bípedes que tinham mania de construir casas onde ela desliza, onde a montanha solta blocos e arrasta matérias. Se não entendemos estes processos e aonde eles ocorrem continuamos tendo uma ação totalmente irregular no processo de ocupação, sem nenhum planejamento. Então o que mais vimos nesses processos é a ignorância humana manifestada, e ela se coloca assim não só do ponto de vista de uma ocupação espontânea, mas de todos os processos de exclusão, (ou seria mais adequado de má inclusão?) dessa população em um determinado espaço.

Aquela mesma senhora que deu um depoimento de que morava lá há trinta anos e que nunca tinha acontecido aquilo na vida dela e que ela paga os impostos, é a mesma situação da senhora que hoje não tem nenhuma segurança no processo de habitação.

São questões preocupantes quando observamos que muitas pessoas ainda estão em situação de abrigo em Friburgo. As obras são lentas. O secretário de obras na ultima reunião disse que conseguiu dar conta de oito cicatrizes de um mapa de 200, 300 manchas vermelhas e só foram feitas obras em oito. Isso foi em setembro numa reunião. Nós estamos no verão e na discussão que se realizou foi que se deliberou sobre a realização de um plano de emergência, mas já estamos em setembro e só agora que se pensou em um plano de emergência e tivemos uma chuva em outubro em Friburgo e nas inundações que já ocorreram o rio subiu de novo. Está tudo assoreado, tem muito sedimento solto nas encostas e as galerias pluviais estão todas entupidas e para o funcionamento da cidade a gente esta "confiando em São Pedro" pra dizer: tomara que não chova, porque se chover a gente espera de novo a mesma tragédia. 